\title{
A case of cribriform carcinoma of the skin: a newly described rare condition
}

\author{
Hyun Lee ${ }^{1}$, Chong-Hyun Won ${ }^{2}$, Chan-Sik Park ${ }^{1}$ \\ Departments of ${ }^{1}$ Pathology and ${ }^{2}$ Dermatology, Asan Medical Center, University of Ulsan College of Medicine, Seoul, Korea
}

Primary cribriform carcinoma of the skin is an indolent, rare, adnexal tumor. Although its malignant potential remains uncertain, no recurrence or metastasis has been reported. A 33-year-old man presented with a solitary, erythematous, subcutaneous nodule on the right knee. The clinical impression was epidermal cyst, and the resected tumor demonstrated a well-circumscribed mass in the dermis and subcutis. The tumor was composed of two regions: a solid component and a cribriform component. The solid component (90\%) showed multiple solid nests of epithelial cells. Individual cells had large, oval-to-round, hyperchromatic, pleomorphic nuclei with a nuclear groove. The cribriform component (10\%) showed similar neoplastic cells with many prominent lumina. Some lumina had an eosinophilic substance that exhibited a positive periodic acid-Schiff reaction. No recurrence or metastasis was observed within a followup period of eight months after excision. In conclusion, we report the first case of primary cribriform carcinoma of the skin in Korea.

Key Words: Cribriform carcinoma; Apocrine tumor; Skin tumor

Received: August 10, 2020 Revised: September 13, 2020 Accepted: October 5, 2020

Corresponding Author: Chan-Sik Park, MD, PhD, Department of Pathology, Asan Medical Center, University of Ulsan College of Medicine, 88 Olympic-ro 43-gil, Songpa-gu, Seoul 05505, Korea

Tel: +82-2-3010-5838, Fax: +82-2-472-7898, E-mail: csikpark@amc.seoul.kr

Cribriform carcinoma of the skin (primary cutaneous cribriform carcinoma [PCCC] is an indolent, rare, adnexal tumor with a presumed apocrine lineage. The first global case was described in 1998 [1], and the most recent (4th) World Health Organization (WHO) classification for skin now includes this condition. Currently, only 42 cases have been reported in the English literature (Table 1) [1-7]. The female-to-male ratio is 2:1, with a median age of 47 years (range, 20 to 77 years). Most cases involve the extremities (85\%). Although its malignant potential remains uncertain, no recurrence or metastasis has been reported.

Herein, we report the first Korean case of primary cribriform carcinoma of the skin.

\section{CASE REPORT}

A 33-year-old man presented with a solitary, erythematous, subcutaneous nodule on the right knee (Fig. 1A), which had developed a few months prior. The clinical impression was epidermal cyst. His past medical history comprised intracranial hemorrhage due to arteriovenous malformation 10 years previous.
After the patient underwent systemic evaluation, including positron emission tomography-computed tomography (PET-CT) and gastric endoscopy, the mass was confirmed as a primary skin tumor, and resection was performed. The resected tumor was a well-circumscribed, yellowish-white, fibrotic, firm, $2.0 \times 1.2 \times$ 0.7-cm mass (Fig. 1B).

Histologically, the tumor was a well-circumscribed mass of the dermis and subcutis. The tumor was composed of (Fig. 2A) a predominantly solid component (90\%) and a predominantly cribriform component (10\%). The solid component showed multiple solid nests of epithelial cells. Individual cells had large, oval-to-round, hyperchromatic, pleomorphic nuclei with a nuclear groove (Fig. 2B). The cytoplasm was eosinophilic and scant. The cribriform component showed similar neoplastic cells with many prominent lumina, giving rise to a cribriform pattern with a thin, thread-like, intraluminal bridge (Fig. 2C). Some lumina had an eosinophilic substance that exhibited a positive periodic acid-Schiff reaction (Fig. 2D). At the periphery of the tumor, multifocal lymphoid aggregates (Fig. 2E), desmoplastic reaction, and some infiltrative tumor cell clusters were present (Fig. 2F). 


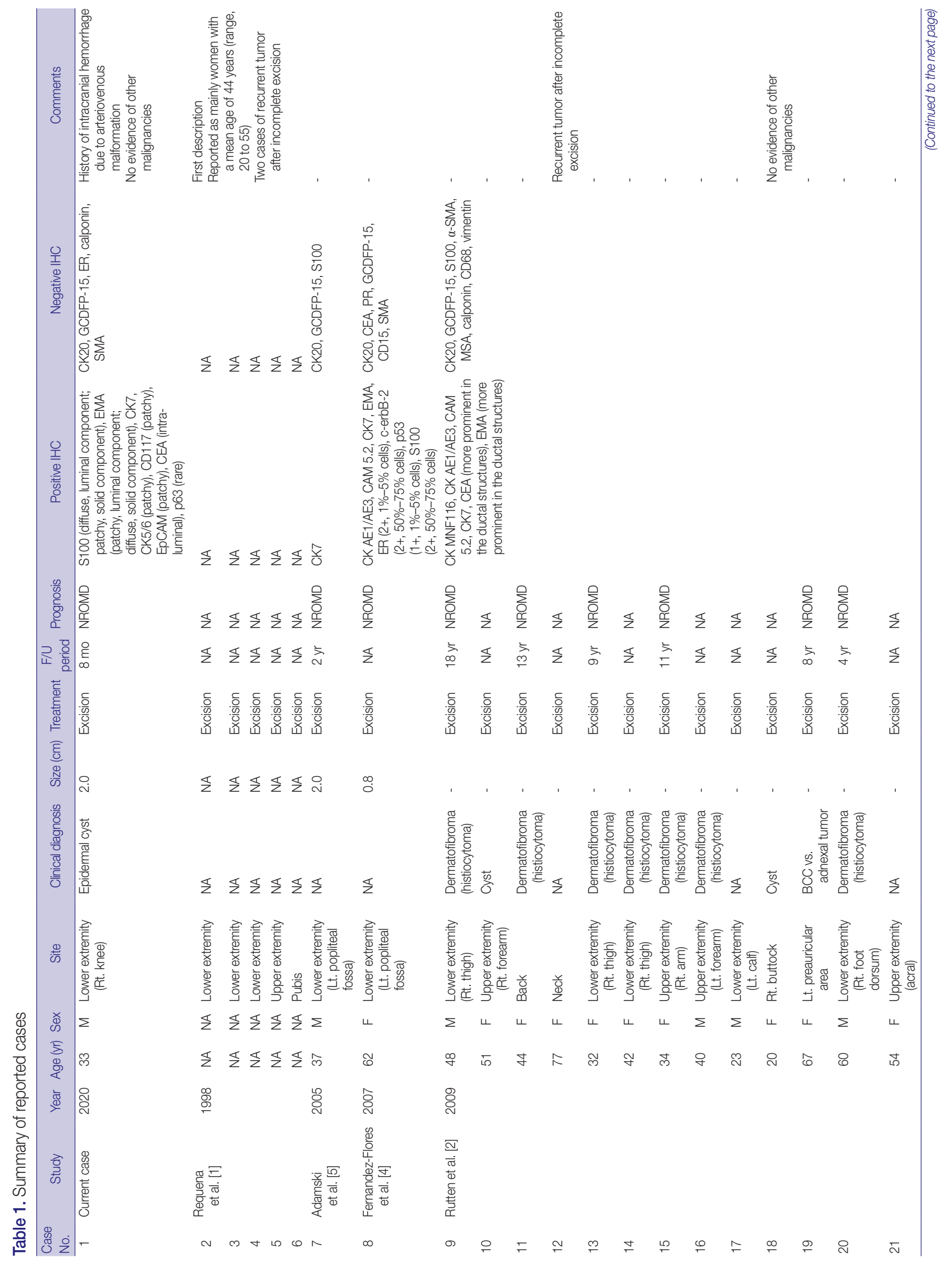


Lee $\mathrm{H}$ et al.

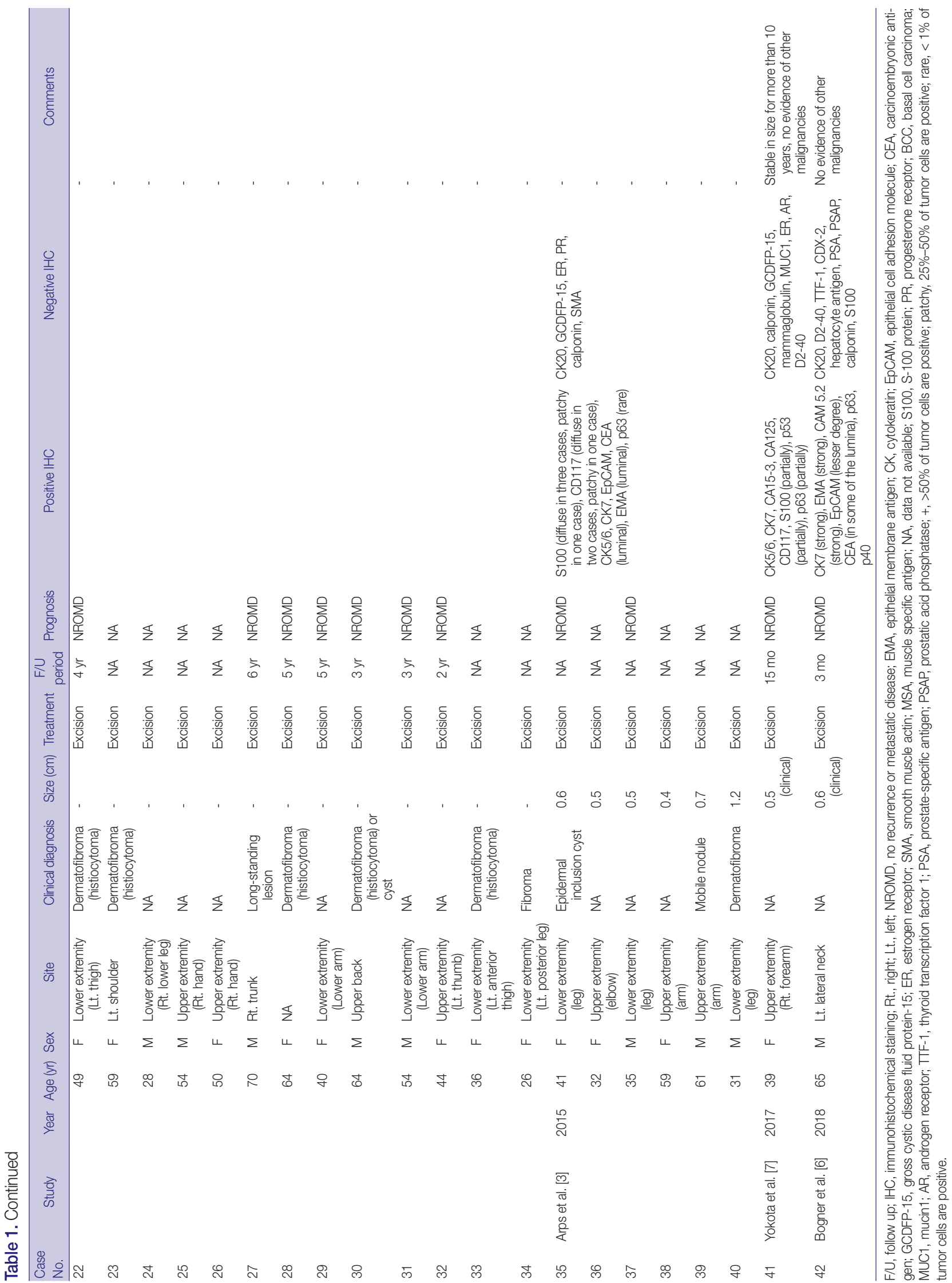




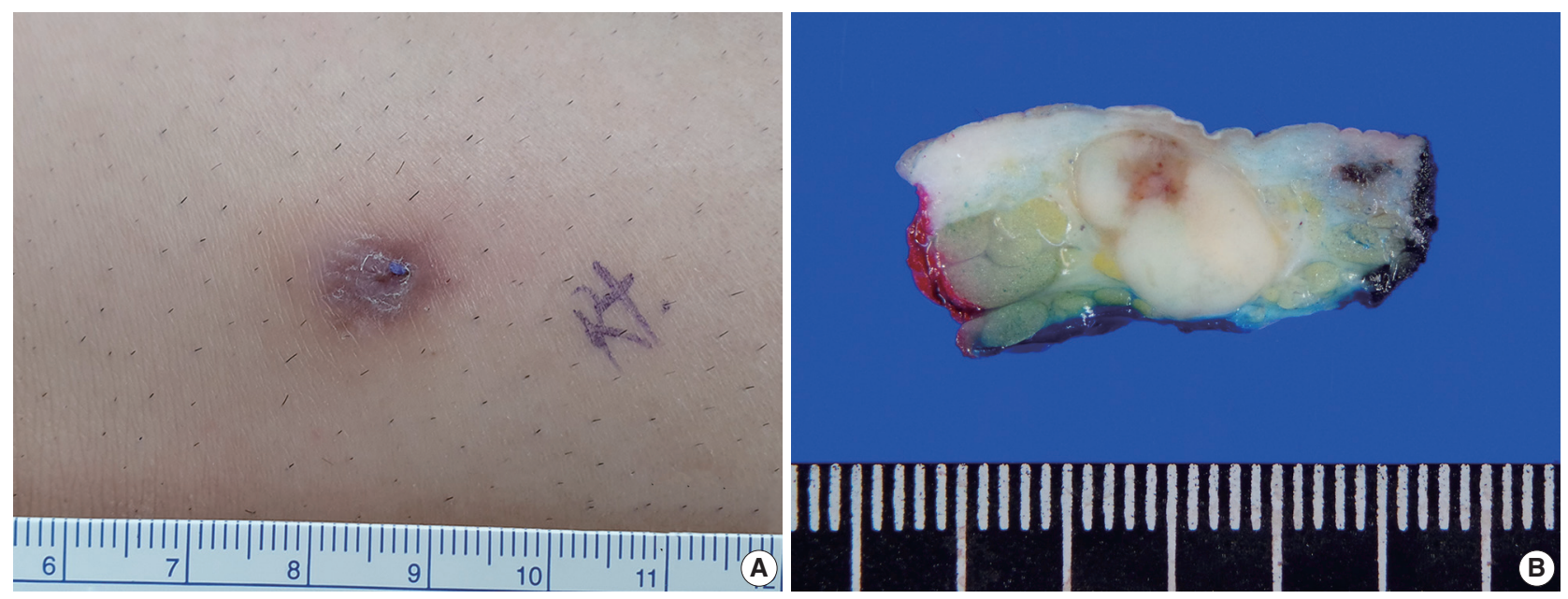

Fig. 1. Gross appearance of the mass. (A) A solitary, erythematous, subcutaneous nodule on the right knee. (B) The cut surface of the mass is well-circumscribed, yellowish-white, fibrotic, and firm.

The epidermis was neither involved with nor connected to the tumor.

The two components of the tumor displayed distinctive immunohistochemical staining patterns for epithelial membrane antigen (EMA) (Fig. 3A) and S-100 protein (Fig. 3B). The predominantly solid component exhibited diffuse immunopositivity for EMA and focal immunopositivity for S100 protein, while the predominantly luminal component exhibited focal immunopositivity for EMA and diffuse immunopositivity for S-100 protein.

Given its histopathologic features, the mass was diagnosed as PCCC. No recurrence or metastasis was observed within a follow-up period of 8 months after excision.

\section{DISCUSSION}

PCCC is a rare, newly described, unique, adnexal neoplasm with an indolent clinical course. Currently, no recurrence or metastasis has been reported. In few cases, remnants have been reported after incomplete excision $[1,3]$. Accurate diagnosis and exclusion of metastasis are important for avoiding over-treatment.

In cases of primary skin neoplasms, the differential diagnosis should include tumors that can show a cribriform pattern: adenoid cystic carcinoma, secretory carcinoma, and tubular adenoma (eccrine papillary adenoma). The histopathologic features for differential diagnoses are listed in Table 2. Adenoid cystic carcinoma can be distinguished by the presence of basaloid epithelial cells with more uniform nuclei surrounding the pseudolumina. The presence of frequent perineural invasion and small true ducts with myoepithelial cell differentiation are points of differential diagnosis. Secretory carcinoma exhibits tubules and microcysts with conspicuous intraluminal secretions, but backto-back proliferation and cuboidal neoplastic cells are characteristic compared with PCCC. Tubular adenoma can show dilated cystic spaces with attenuated epithelium, micro-papillae, and focal intraluminal bridging, mimicking PCCC. However, this condition lacks cytologic atypia and mitotic activity and involves accumulation of basal/myoepithelial cells.

Histopathologically, metastatic tumors that show a cribriform pattern shold be excluded. A cribriform pattern can be seen in cancers of various organs, including the breast (adenoid cystic carcinoma and cribriform adenocarcinoma), prostate (ductal carcinoma and acinar carcinoma), stomach, colon, lung, thyroid (cribriform-morular variant of papillary thyroid carcinoma), uterine endometrium, and salivary gland [8-10]. To exclude metastasis, imaging studies, such as PET-CT and CT, and immunohistochemical staining are required.

Immunohistochemical staining results are listed in Table 1. Although decapitation secretion in the luminal border supports apocrine differentiation, gross cystic disease fluid protein-15, a marker for the apocrine gland, was negative in previous reports [1-7] and in our case. The S-100 protein, a marker for the eccrine gland, demonstrated variable results (diffuse positive, focal positive, and negative) in previous reports [1-7]. Our case showed more prominent S-100 protein in the luminal component. EMA was positive in previous reports [1-7]. Rutten et al. [2] reported more prominent EMA in the luminal structures, while our case showed more prominent EMA in the solid component.

The relatively mutually exclusive immunohistochemical staining patterns of EMA and S-100 protein may be associated with 

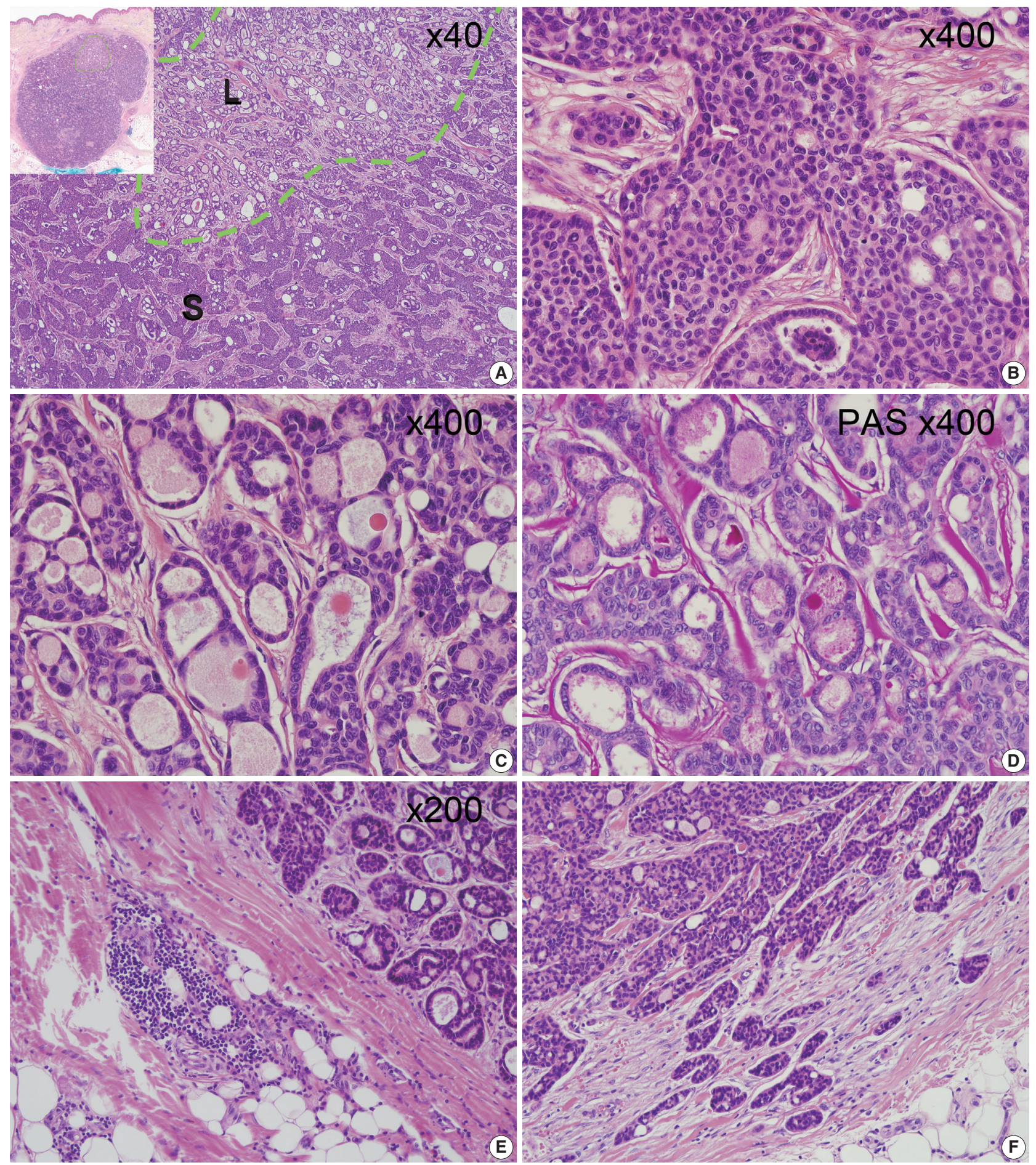

Fig. 2. Histopathologic features of the mass. (A) The mass exhibited a predominantly solid component (90\%) and a predominantly cribriform component (10\%, inside the green line). (B) The predominantly solid component revealed pleomorphic nuclei. (C) The predominantly cribriform component had similar cytologic features to those of the solid component and demonstrated many prominent small lumina with a thin thread-like intraluminal bridge (cribriform pattern) along with an occasional eosinophilic substance. (D) The intraluminal eosinophilic substance with periodic acid-Schiff reaction. (E) Multifocal lymphoid aggregates at the periphery. (F) Infiltrative tumor clusters at the periphery. S, predominantly solid component; L, predominantly luminal component. 
architectural differentiation, and further research is needed.

In conclusion, we report the first case of cribriform carcinoma of the skin in Korea. Pathologists should be aware of cribriform carcinoma of the skin to avoid over-treatment.
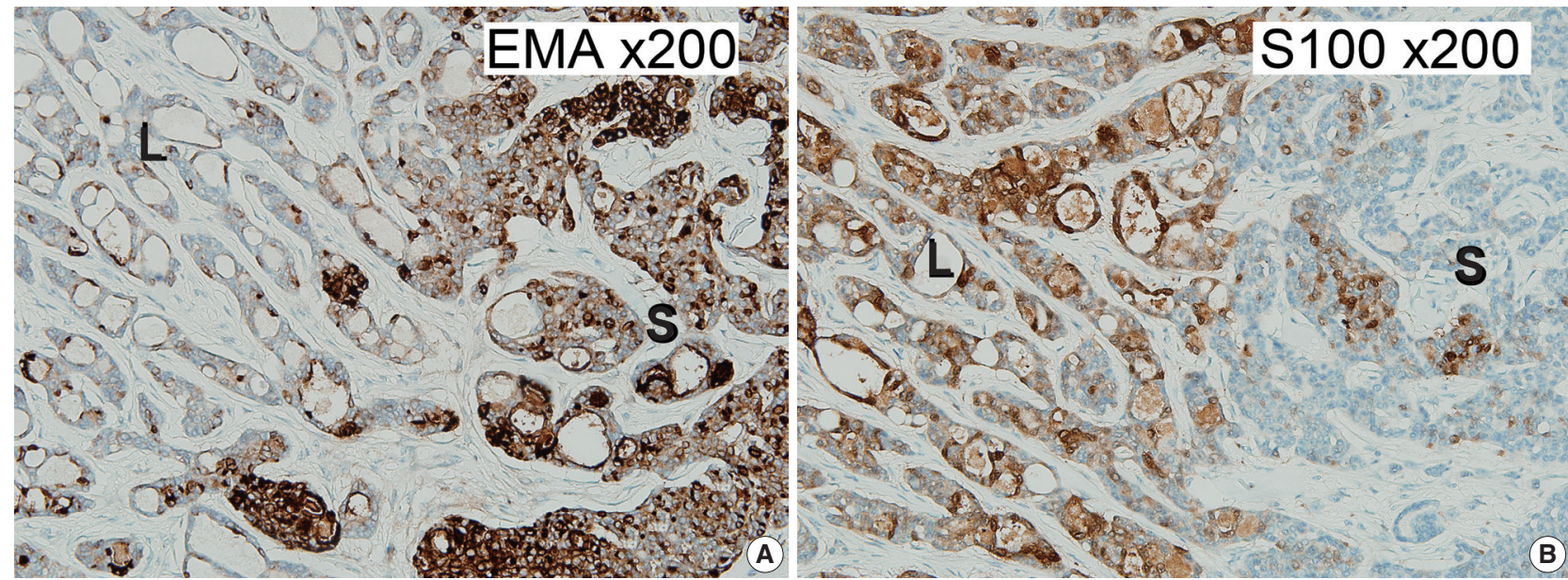

Fig. 3. Results of immunohistochemical $(\mathrm{IHC})$ staining. $(\mathrm{A}) \mathrm{HHC}_{\mathrm{H}}$ for epithelial membrane antigen: diffuse immunopositivity for the predominantly solid component (on the right) and focal immunopositivity for the predominantly luminal component (on the left). (B) IHC for S-100 protein: diffuse immunopositivity for the predominantly luminal component (on the left) and focal immunopositivity for the predominantly solid component (on the right). S, predominantly solid component; L, predominantly luminal component.

Table 2. Histopathologic characteristics of cribriform carcinoma and similar tumors

\begin{tabular}{|c|c|c|c|c|}
\hline & Cribriform carcinoma & Adenoid cystic carcinoma & Secretory carcinoma & Tubular adenoma \\
\hline \multirow[t]{5}{*}{ Architecture } & Usually well-circumscribed & Poorly circumscribed & Intradermal, circumscribed & Well circumscribed \\
\hline & $\begin{array}{l}\text { Mixed variable portion of solid } \\
\text { and cribriform }\end{array}$ & $\begin{array}{l}\text { Composed of lobules, islands, } \\
\text { and cords of basaloid cells } \\
\text { with numerous cystic and } \\
\text { ductular spaces }\end{array}$ & $\begin{array}{l}\text { Back-to-back proliferation of } \\
\text { tubules and microcysts }\end{array}$ & $\begin{array}{l}\text { Variable sized tubules with } \\
\text { attenuated epithelium }\end{array}$ \\
\hline & No back-to-back appearance & & Cuboidal cells & $\begin{array}{l}\text { Micro-papillae, and focal } \\
\text { intraluminal bridging }\end{array}$ \\
\hline & No cuboidal cells & & \multirow[t]{2}{*}{ Sclerotic stroma } & \multirow{2}{*}{$\begin{array}{l}\text { Paucicellular fibrous stroma } \\
\text { Recognition of myoepithelial } \\
\text { layer }\end{array}$} \\
\hline & Desmoplastic stroma & & & \\
\hline $\begin{array}{l}\text { Intra-(pseudo) luminal } \\
\text { substance }\end{array}$ & $\begin{array}{l}\text { Eosinophilic substance with } \\
\text { PAS reaction }\end{array}$ & $\begin{array}{l}\text { Mucin or basement membrane } \\
\text { material that stains with } \\
\text { mucicarmine, Alcian blue, } \\
\text { and colloidal iron }\end{array}$ & $\begin{array}{l}\text { Conspicuous intraluminal } \\
\text { secretions }\end{array}$ & $\begin{array}{l}\text { Eosinophilic proteinaceous } \\
\text { material }\end{array}$ \\
\hline Nuclei & Pleomorphic & Uniform & Mildly pleomorphic & Uniform \\
\hline Mitosis & Rare & Rare & Rare to few & Absent \\
\hline Perineural invasion & Absent & Present, frequent & Absent & Absent \\
\hline \multirow[t]{3}{*}{$\begin{array}{l}\text { Immunohistochemical } \\
\text { staining }\end{array}$} & $\begin{array}{c}\text { Variable CK (MNF116, AE1/ } \\
\text { AE3, CAM5.2, and CK7) }\end{array}$ & EMA and monoclonal CEA & $\begin{array}{l}\text { S100 protein, mammaglobin } \\
\text { and STAT5A }\end{array}$ & HMFG-1 and GCDFP-15 \\
\hline & EpCAM & $\begin{array}{l}\text { S100, p63, GFAP, SMA, MSA } \\
\text { and calponin: often stain } \\
\text { peripheral cells (myoepithelial } \\
\text { differentiation) }\end{array}$ & NTRK3: variable & EMA and CEA: luminal cells \\
\hline & $\begin{array}{l}\text { CD117, S100, and } \\
\text { p63: variable } \\
\text { CEA, EMA: highlight ductal } \\
\text { component }\end{array}$ & & & $\begin{array}{l}\text { S100 and SMA: myoepithelial } \\
\text { cells }\end{array}$ \\
\hline Reference & {$[11,12]$} & {$[12,13]$} & {$[12,14]$} & {$[3,12,13]$} \\
\hline
\end{tabular}

PAS, periodic acid-Schiff; CK, cytokeratin; EMA, epithelial membrane antigen; CEA, carcinoembryonic antigen; S100, S-100 protein; GCDFP-15, gross cystic disease fluid protein-15; EpCAM, epithelial cell adhesion molecule; GFAP, glial fibrillary acidic protein; SMA, smooth muscle actin; MSA, muscle specific antigen. 


\section{Ethics Statement}

This study was approved by the Institutional Review Board of Asan Medical Center (IRB 2020-0364). Formal written informed consent was not required, with a waiver from the appropriate Institutional Review Board.

\section{ORCID}

Hyun Lee Chong-Hyun Won

https://orcid.org/0000-0001-7005-8142

Chan-Sik Park

https://orcid.org/0000-0003-1997-2240

https://orcid.org/0000-0001-9783-4498

\section{Author Contributions}

Conceptualization: CSP. Data curation: HL. Formal analysis: HL. Funding acquisition: CSP. Investigation: CSP. Methodology: HL. Resources: WCH. Supervision: CSP. Validation: CSP, HL. Writing-original draft: HL. Writing-review \& editing: CSP. Approval of final manuscript: all authors.

\section{Conflicts of Interest}

CSP, a contributing editor of the Journal of Pathology and Translational Medicine, was not involved in the editorial evaluation or decision to publish this article. All remaining authors have declared no conflicts of interest.

\section{Funding Statement}

No funding to declare.

\section{References}

1. Requena L, Kiryu H, Ackerman AB. Neoplasms with apocrine differentiation. Philadelphia: Lippincott-Raven, 1988; 879-905.

2. Rutten A, Kutzner H, Mentzel T, et al. Primary cutaneous cribriform apocrine carcinoma: a clinicopathologic and immunohistochemical study of 26 cases of an under-recognized cutaneous adnexal neoplasm. J Am Acad Dermatol 2009; 61: 644-51.

3. Arps DP, Chan MP, Patel RM, Andea AA. Primary cutaneous crib- riform carcinoma: report of six cases with clinicopathologic data and immunohistochemical profile. J Cutan Pathol 2015; 42: 379-87.

4. Fernandez-Flores A, Pol A, Juanes F, Crespo LG. Immunohistochemical phenotype of cutaneous cribriform carcinoma with a panel of 15 antibodies. Med Mol Morphol 2007; 40: 212-7.

5. Adamski H, Le Lan J, Chevrier S, Cribier B, Watier E, ChevrantBreton J. Primary cutaneous cribriform carcinoma: a rare apocrine tumour. J Cutan Pathol 2005; 32: 577-80.

6. Bogner R, Brown T, Fearneyhough P, Gataky G. Primary cutaneous cribriform carcinoma treated with mohs micrographic surgery. Dermatol Surg 2018; 44: 583-5.

7. Yokota K, Kono M, Mori S, Shimizu K, Matsumoto T, Akiyama M. A solid variant of primary cutaneous cribriform carcinoma: a small, stable, long-term lesion. Eur J Dermatol 2017; 27: 419-21.

8. Branca G, Ieni A, Barresi V, Tuccari G, Caruso RA. An updated review of cribriform carcinomas with emphasis on histopathological diagnosis and prognostic significance. Oncol Rev 2017; 11:317.

9. Page DL, Dixon JM, Anderson TJ, Lee D, Stewart HJ. Invasive cribriform carcinoma of the breast. Histopathology 1983; 7: 525-36.

10. McNeal JE, Reese JH, Redwine EA, Freiha FS, Stamey TA. Cribriform adenocarcinoma of the prostate. Cancer 1986; 58: 1714-9.

11. Requena L, Sangueza O. Cribriform carcinoma. In: Requena L, Sangueza O, eds. Cutaneous adnexal neoplasms. Cham: Springer, 2017; 313-20.

12. Elder DE, Massi D, Scolyer RA, Willemze R. WHO classification of skin tumours. Lyon: IARC Press, 2018.

13. Cassario D. Diagnostic pathology: neoplastic dermatopathology. Salt Lake City: Amirsys Publishing Inc., 2012.

14. Llamas-Velasco M, Mentzel T, Rutten A. Primary cutaneous secretory carcinoma: a previously overlooked low-grade sweat gland carcinoma. J Cutan Pathol 2018; 45: 240-5. 